\title{
A kinematic model of infiltration and runoff generation in layered and sloped soils
}

\author{
Mariza C. Cabral, Luis Garrote, Rafael L. Bras \& Dara Entekhabi \\ Department of Civil and Environmental Engineering, Ralph M. Parsons Laboratory, Massachusetts Institute of Technology'. \\ Cambridge, Massachusetts 02139, USA
}

\begin{abstract}
A model of infiltration, subsurface lateral flow and surface runoff generation that considers the effects of anisotropy and vertical heterogeneity is developed. The flow relations are based on the kinematic approximation and account for the influence of terrain slope. The model consists of equations for the evolution of the wetting front, the growth of the perched saturation zone, and the rate of unsaturated and saturated lateral subsurface flow.
\end{abstract}

Key words: distributed watershed modeis, infiltration. runoff generation.

\section{INTRODUCTION}

It has long been recognized that infiltrating rainfall on a hillslope results in subsurface flow lines that often are not vertical, but have a downslope component. This paper is motivated by the runoff-generation implications of subsurface flow geometry, with flood forecasting as the ultimate goal. Lateral subsurface flux originating during a rainfall event may generate storm runoff by two different mechanisms. First, lateral flux may emerge at the surface under certain conditions, becoming overland flow. This is subsurface storm runoff and it may represent a significant portion of the storm hydrograph. Second, lateral subsurface flux leads to moisture concentration at the bottom of the hillslopes, especially if the hillslopes are concave and convergent. Commonly the bottom of these hillslopes are also areas of shallow water table, and therefore subsurface inputs to these areas, combined with direct rainfall, cause rapid water table rise and the development and growth of saturated areas that are effectively impermeable to rainfall. From this perspective, topography plays an important role in storm runoff generation. The availability of detailed topographical information in the form of digital elevation models (DEM) facilitates the use of topography in a distributed flood simulation model. However, in order to obtain a distributed model that can operate at the fine resolution given by DEMs it is necessary to develop a computationally efficient model of infiltration that can represent the most relevant

Advances in Water Resources 0309-1708/93/\$06.00

C 1993 Elsevier Science Publishers Ltd. features of the subsurface flow from the standpoint of storm runoff generation. The infiltration model should nevertheless include the role of sloped terrains, anisotropic soil layering and other factors distributing moisture in the vertical soil column.

Capillary forces, soil layering, anisotropy and slope are the main mechanisms through which flow deviations from the vertical have been explained in the literature. Zaslavsky and Rogowski ${ }^{14}$ introduced some qualitative and quantitative considerations in modeling the influence of anisotropy and terrain slope on the magnitude and direction of unsaturated downhill flow. Zaslavsky and Sinai ${ }^{15}$ studied the effects of soil heterogeneity, specifically soils consisting of distinct and plane-parallel layers. Successive layers of homogeneous and isotropic soil with different hydraulic properties behave as a nonisotropic soil matrix with a resultant downstream flow component parallel to the soil surface. McCord and Stephens ${ }^{8}$ analyzed soil moisture data from an experimental basin in order to characterize the influence of topography on subsurface lateral flow paths in the unsaturated zone.

An infinite-series solution to the full equation of flow in a homogeneous, anisotropic, and sloped soil was presented by Philip. ${ }^{10} \mathrm{He}$ found that total horizontal unsaturated flow is generally directed into the hillslope for isotropic soils. The integrated resultant flow, nevertheless, has a constant downslope component which is proportional to the square root of time for small times. He also considered two types of anisotropy. In the first type the principal directions of anisotropy are parallel and normal to the soil surface. In the second type, principal directions of anisotropy are horizontal 
and vertical. Philip ${ }^{10}$ found markedly different behavior in both cases, each component of the flow obtained for the isotropic case, the parallel or the horizontal, is magnified by the anisotropy ratio.

Series and numerical solutions to the flow equation provide a good insight to the main features of the physical description of the phenomenon, but they are computationally too complex to be included in distributed basin-scale models. In this paper, several simplifying assumptions are made in order to obtain a simple analytical solution feasible for application at the basin scale. Runoff generation during floods is of concern, and therefore an adequate mapping of the saturated areas is the main objective of the model. Rainfall over these saturated subregions is responsible for a large fraction of the peak in the storm hydrograph.

The case analyzed here is similar to that in Philip, ${ }^{10}$ considering anisotropy parallel to the hillslope for a particular case of soil heterogeneity. The simplification introduced consists of neglecting the effect of capillary forces in unsaturated infiltration in what is usually referred to as the kinematic approximation. Kinematic infiltration has been studied in the context of gravitydominated flow in homogeneous and isotropic soils. ${ }^{3.5 .11}$ It has been found to be an adequate approximation to obtain subsurface stormflow by Beven' for a wide range of values of hydraulic conductivity and terrain slope. Here we consider kinematic infiltration in anisotropic soils within sloping surfaces where the saturated hydraulic conductivity decreases exponentially with depth. For the sake of mathematical tractability, it is assumed that the soil column has a large length scale in the direction of its surface slope so that boundary conditions do not have an effect on local infiltration. Philip ${ }^{10}$ found this assumption not too restrictive for most practical cases. However, this assumption should be revised for application in a distributed model, since the spatial variability of hillslope geometry and soil properties introduce lateral flow gradients. Here only variabilities in the direction normal to the slope are considered, although the proposed model describes the twodimensional flow within a hillslope for these planeparallel conditions.

\section{SOIL MODEL}

Flow equations are derived in the reference system defined by the directions normal $(n)$ and parallel $(p)$ to the slope; $\mathbf{i}_{n}$ and $\mathbf{i}_{p}$ are unit vectors in these directions. The distance $n$ is taken positive in the downward direction and $p$ is taken positive in the downslope direction. Flow is also described in the alternative reference system defined by the vertical $(z)$ and horizontal $(x)$ directions. $\mathbf{i}_{z}$ and $\mathbf{i}_{x}$ are unit vectors in

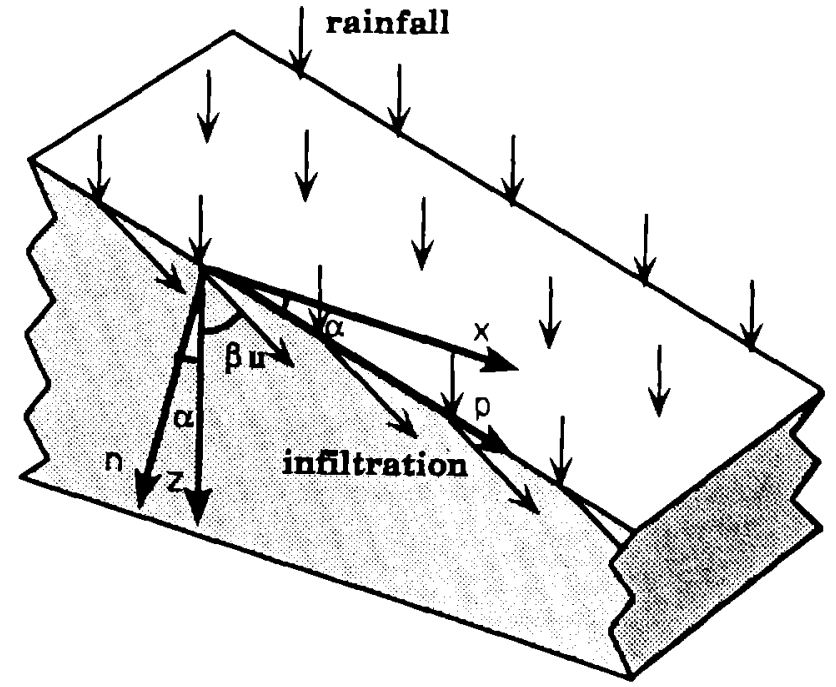

Fig. 1. Representation of the coordinate directions on a hillslope of constant slope, $\tan \alpha$. Axis $p$ is parallel to the hillslope surface and points in the direction of maximum slope. Axis $n$ is normal to the hillslope surface. Axis $x$ is the projection of axis $p$ on the horizontal plane. Axis $z$ is in the vertical direction. Infiltration may be at an angle $\beta_{u}$ with respect to the vertical direction, as represented.

these directions. The two reference systems form an angle $\alpha$, the angle of terrain surface (see Fig. 1).

The analytical solutions to the kinematic infiltration are developed for the following model of the soil column.

(1) The soil is sloped at an angle $\alpha$ with respect to the horizontal direction. Soil characteristics may vary only in the direction normal to the surface. The terrain model is therefore layered parallel to the surface.

(2) Saturated hydraulic conductivity decreases with depth normal to the sloped surface. The decrease of hydraulic conductivity with depth is a key assumption in the model, since it is the mechanism that leads to the formation of a perched saturated zone. Different functional forms could be adopted to parameterize the variation of hydraulic conductivity with depth. Here we adopt an exponential decrease with normal depth. Beven $^{2}$ found that a number of soil data sets from a variety of basins were well represented by such a model of hydraulic conductivity. Similar results could be obtained considering other formulations, such as polynomials or piecewise linear functions. However, other possible parametrizations exhibit sharp edges, or discontinuities, or lead to a larger number of parameters. Although not all soil profiles show an exponential decrease of hydraulic conductivity with depth, the exponential assumption is common practice in hydrology, and it is adopted here as a parsimonious way of representing variability in the vertical.

The directions parallel and normal to the soil surface are the main directions of the hydraulic conductivity tensor, and for them, the saturated hydraulic 
conductivities are given by

$$
\begin{aligned}
& K_{\mathrm{s}_{n}}(n)=K_{0_{n}} \mathrm{e}^{-f n} \\
& K_{\mathrm{s}_{p}}(n)=K_{0_{r}} \mathrm{e}^{-f n}
\end{aligned}
$$

where $K_{\mathrm{S}_{n}}(n)$ and $K_{\mathrm{s}_{p}}(n)$ are the saturated conductivities at depth $n$ perpendicular and parallel to the surface; $K_{0_{n}}$ and $K_{0}$ are the saturated hydraulic conductivities in directions $n$ and $p$ at the soil surface; and $f$ is a parameter of dimension $\left[\mathrm{L}^{-1}\right]$. The parameter $f$ controls the decay of the saturated hydraulic conductivity with depth.

The saturated hydraulic conductivities in directions $n$ and $p$ are related through the dimensionless anisotropy ratio $a_{\mathrm{r}}$, defined as

$$
a_{\mathrm{r}}=\frac{K_{0_{r}}}{K_{0_{n}}}>1
$$

This relationship is assumed to be valid for all depths.

(3) The Brooks-Corey ${ }^{4}$ parameterization of unsaturated hydraulic conductivity is used. Upon substitution of eqns ( $1 \mathrm{a})$ and $(\mathrm{lb})$ for the saturated conductivities in directions $n$ and $p$, the Brooks-Corey parametrization gives

$$
\begin{aligned}
& K_{n}(\theta, n)=K_{0_{n}} \mathrm{e}^{-f n}\left(\frac{\theta-\theta_{\mathrm{r}}}{\theta_{\mathrm{s}}-\theta_{\mathrm{r}}}\right)^{\epsilon} \\
& K_{p}(\theta, n)=K_{0_{p}} \mathrm{e}^{-f n}\left(\frac{\theta-\theta_{\mathrm{r}}}{\theta_{\mathrm{s}}-\theta_{\mathrm{r}}}\right)^{\epsilon}
\end{aligned}
$$

where $K_{n}(\theta, n)$ and $K_{p}(\theta, n)$ are the hydraulic conductivities in directions $n$ and $p$ at moisture content $\theta$ and at depth $n ; \theta_{\mathrm{s}}$ is the saturated moisture content; $\theta_{\mathrm{r}}$ is the residual moisture content, defined as the value below which moisture is immobile; and $\epsilon$ is a pore size distribution index.

There is correlation between each of the parameters $\theta_{\mathrm{r}}, \theta_{\mathrm{s}}$, and $\epsilon$ and the saturated hydraulic conductivity. For saturated conductivity varying with depth, these parameters should correspondingly be functions of depth. Nevertheless, parameters $\theta_{\mathrm{r}}, \theta_{\mathrm{s}}$, and $\epsilon$ have less variability for different soil types.6, 9 Their vertical variability is more difficult to characterize than that of hydraulic conductivity, and for simplicity we consider them to be constant with depth, but different for every soil type. The same approach has been adopted by other authors (see, e.g., Refs 7 and 13). Given these considerations, it is evident that anisotropy of saturated conductivities is duplicated for unsaturated flow as well.

\section{ANALYSIS OF UNSATURATED FLOW}

When the rainfall rate is lower than the initial infiltration capacity, the movement of water in the soil column occurs under unsaturated conditions. In a soil where conductivity decreases with depth, perched saturation may develop under prolonged infiltration.
All equations presented in this section refer to flow in the unsaturated region from the surface to the wetting front in the early stages of infiltration. Flow under saturated conditions is the subject of Section 4 .

\subsection{Flow geometry}

The flow vector $\mathbf{q}$ may be expressed in terms of its components in the main directions of anisotropy,

$$
\mathbf{q}=q_{n} \mathbf{i}_{n}+q_{p} \mathbf{i}_{p}=-K_{n} J_{n} \mathbf{i}_{n}-K_{p} J_{p} \mathbf{i}_{p}
$$

where $q_{n}$ and $q_{p}$ are the components of discharge per unit area in directions $n$ and $p$ and $J_{n}$ and $J_{p}$ are the components of the hydraulic gradient vector $\mathbf{J}$ in those directions. If the soil is unsaturated, water pressure is less than atmospheric, because it is affected by surface tension. However, under the kinematic assumption the effect of negative water pressure due to capillarity is neglected and the hydraulic gradient is only gravitational,

$$
\mathbf{J}=J_{n} \mathbf{i}_{n}+J_{p} \mathbf{i}_{p}=-\cos (\alpha) \mathbf{i}_{n}-\sin (\alpha) \mathbf{i}_{p}
$$

Substituting $J_{n}$ and $J_{p}$ given by eqn (5) into eqn (4), and using eqn (2), we write

$$
\begin{aligned}
\mathbf{q} & =K_{n} \cos (\alpha) \mathbf{i}_{n}+K_{p} \sin (\alpha) \mathbf{i}_{p} \\
& =K_{n} \cos (\alpha) \mathbf{i}_{n}+a_{\mathrm{r}} K_{n} \sin (\alpha) \mathbf{i}_{p}
\end{aligned}
$$

Soil anisotropy deflects the unsaturated flow at an angle, designated $\beta_{u}$, with respect to the direction of the hydraulic gradient (the subscript in $\beta_{\mathrm{u}}$ is used to indicate unsaturated infiltration). From Fig. 2 and eqns (2), (4) and (6),

$$
\tan \left(\alpha+\beta_{\mathrm{u}}\right)=\frac{q_{p}}{q_{n}}=a_{\mathrm{r}} \tan \alpha
$$

Solving for $\beta_{\mathrm{u}}$,

$$
\beta_{\mathrm{u}}=\tan ^{-1}\left(a_{\mathrm{r}} \tan \alpha\right)-\alpha
$$

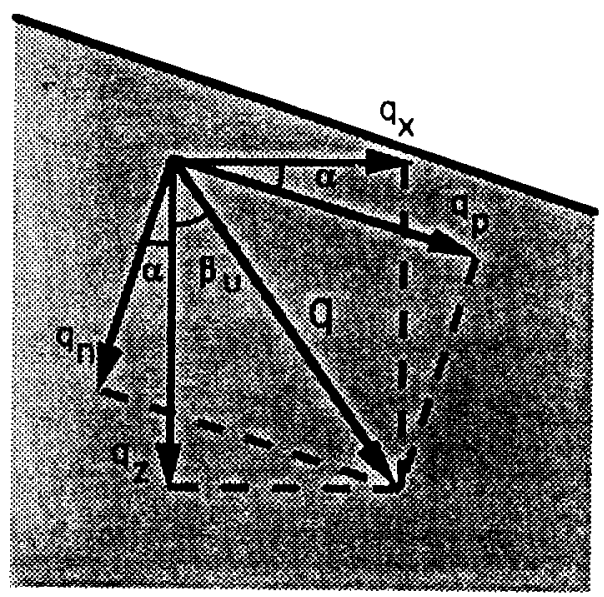

Fig. 2. Components of flow in the $z$ and $x$, and $n$ and $p$ directions. Flow is in the direction indicated by the vector $\mathbf{q}$. 
Angle $\beta_{\mathrm{u}}$ is constant with depth since the ratio $a_{\mathrm{r}}$ is constant with depth. The angle $\alpha+\beta_{\mathrm{u}}$ is larger for higher anisotropy ratios and steeper terrain slopes. For $a_{\mathrm{r}}=1$, eqn (8) gives $\beta_{\mathrm{u}}$ equal to zero. That is, for an isotropic soil the above equations give unsaturated flow strictly in the vertical direction.

Since flow direction is constant in the unsaturated area, we can derive an expression for the steady state flow vector $\mathbf{q}$ from continuity considerations. Let us consider rainfall at a rate $R$. In steady state there must be no moisture changes in the soil. From continuity, the flow per unit width perpendicular to segment $a$ (which has unit length) must equal the flow per unit width perpendicular to segment $b$ in Fig. 3. Designating the direction of the resultant flow vector by $s$, we obtain

$$
R a=q_{s} b
$$

From geometrical considerations, we can write

$$
b=\frac{\cos \left(\alpha+\beta_{\mathrm{u}}\right)}{\cos \alpha}
$$

Substituting eqn (9) into eqn (10) and solving for $q_{s}$ we obtain

$$
q_{s}=\frac{\cos \alpha}{\cos \left(\alpha+\beta_{u}\right)} R
$$

The component of flow in the normal direction, $q_{n}$, is related geometrically to $q_{s}$ through

$$
q_{n}=\cos \left(\alpha+\beta_{\mathrm{u}}\right) q_{s}
$$

which combines with eqn (11) into

$$
q_{n}=R \cos \alpha
$$

From eqns (13) and (6) we obtain

$$
K_{n}(\theta, n)=R
$$

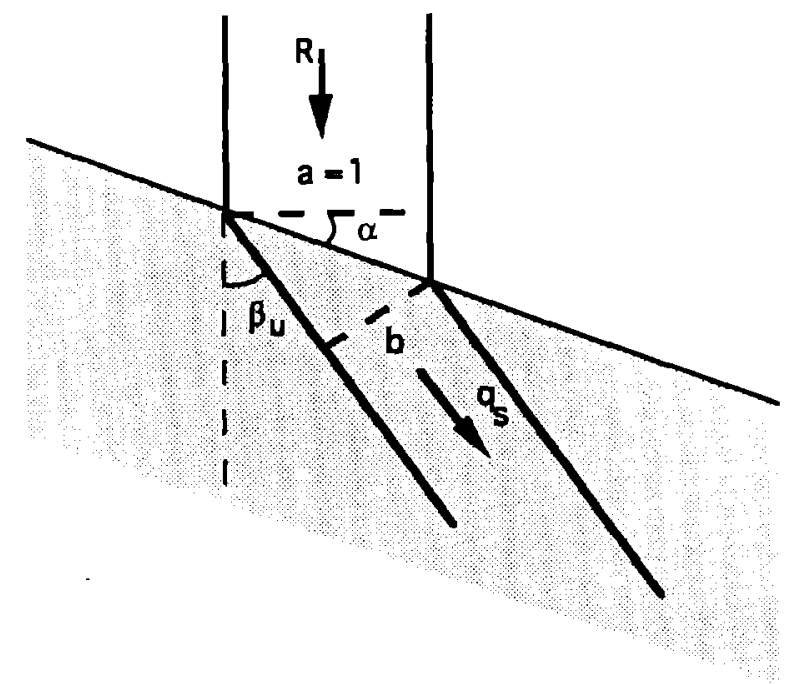

Fig. 3. Steady-state unsaturated infiltration in a sloped and anisotropic soil.

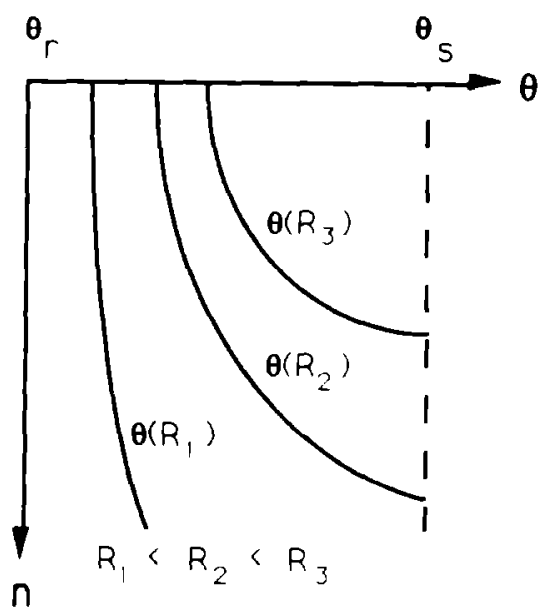

Fig. 4. Moisture profiles for various rainfall rates $\left(R_{1}, R_{2}\right.$ and $R_{3}$ ) lower than the soil surface saturated conductivity. Hydraulic conductivity decreases exponentially with depth.

which is evident for kinematic flow in porous media.

Using the above in eqn (3a) we obtain a description of the soil moisture profile under steady infiltration at rate $R$ :

$$
\theta(R, n)=\left(\frac{R}{K_{0_{n}}}\right)^{1 / \epsilon}\left(\theta_{\mathrm{s}}-\theta_{\mathrm{r}}\right) \exp \left(\frac{f n}{\epsilon}\right)+\theta_{\mathrm{r}}
$$

Equation (15) shows that in steady state conditions, the moisture content above the wetting front increases exponentially with depth, in order to maintain the normal hydraulic conductivity equal to the rainfall rate $R$. Figure 4 represents moisture profiles corresponding to various steady infiltration rates.

Given that saturated soil conductivity decreases with depth, for any rainfall rate $R$ lower than the surface normal hydraulic conductivity $\left(R<K_{0_{0}}\right)$, a corresponding depth within the soil profile $N^{*}(R)$ will have the saturated conductivity in the normal direction equal to the rainfall rate, i.e.

$$
K_{n}\left(\theta_{\mathrm{s}}, N^{*}\right)=R
$$

Substituting $\theta_{\mathrm{s}}$ and $N^{*}$ in the expression for $K_{n}\left(N^{*}\right)$ (eqn (3a)) and solving for $N^{*}$ in eqn (16), we obtain

$$
N^{*}(R)=\frac{1}{f} \ln \left(\frac{K_{0_{n}}}{R}\right)
$$

Note that eqn (17) applies only for $R \leq K_{0_{n}}$. For $R>K_{0_{n}}$, the saturated level is at the surface, and there is no unsaturated area above the wetting front.

Letting $n=N^{*}(R)$ in eqn (15), we obtain $\theta\left(R, N^{*}\right)=\theta_{\mathrm{s}}$. Therefore, $N^{*}(R)$ represents the depth at which saturation develops under a steady infiltration rate $R$. For $n>N^{*}(R)$, we have $K_{\mathrm{s}_{n}}(n)<R$ and the soil can no longer transmit flow at the rate of infiltration to depths beyond $N^{*}(R)$. Water accumulates above that level and perched saturation develops. 


\subsection{Vertical and horizontal components of flow}

Combining eqns (6), (7), (13), and (16) the expression for the flow vector $q$ is

$$
\mathbf{q}=R \cos (\alpha) \mathbf{i}_{n}+a_{\mathrm{r}} R \sin (\alpha) \mathbf{i}_{p}
$$

Vertical and horizontal components of flow are obtained by projecting the flow vector $\mathbf{q}$ on the $z$ and $x$ axes:

$$
\begin{aligned}
q_{z}= & q_{n} \cos \alpha+q_{p} \sin \alpha=(R \cos \alpha) \cos \alpha \\
& +\left(a_{\mathrm{r}} R \sin \alpha\right) \sin \alpha \\
q_{x}= & -q_{n} \sin \alpha+q_{p} \cos \alpha=-(R \cos \alpha) \sin \alpha \\
& +\left(a_{\mathrm{r}} R \sin \alpha\right) \cos \alpha
\end{aligned}
$$

Upon simplification,

$$
\begin{aligned}
& q_{z}=R\left(\cos ^{2} \alpha+a_{r} \sin ^{2} \alpha\right) \\
& q_{x}=R(\cos \alpha \sin \alpha)\left(a_{\mathrm{r}}-1\right)
\end{aligned}
$$

Both vertical and horizontal components of flow are constant over depth. For anisotropy ratios greater than one, horizontal flow goes in the downhill direction and is maximum for slopes at $45^{\circ}$ angle.

\subsection{Wetting front advance in the unsaturated zone}

Equations relevant to the geometry and magnitude of the unsaturated flow have been derived under the steady state assumption. In this section we present the equation for the time evolution of the moisture front in the soil column. We assume that the initial state of the soil can be described by a moisture distribution given by eqn (15) for a small initial infiltration rate $R_{\mathrm{i}}$. We also consider a constant rainfall rate $R, R>R_{\mathrm{i}}$, over a given time interval. Under the kinematic approximation, a sharp discontinuity in moisture content separates the area affected by the propagation of the infiltration wave and the undisturbed area below the front.

We consider that the expression governing the flow of moisture in the unsaturated area in steady state (eqn (18)) is valid for both areas just above and below the wetting front. Furthermore, we assume that the wetting front is parallel to the surface and advances perpendicular to it. Its location below the surface datum is represented by the distance $N_{\mathrm{f}}$ (see Fig. 5). In the initial phase of infiltration, i.e. while $N_{\mathrm{f}}<N^{*}(R)$, the soil between the surface and depth $N_{\mathrm{f}}$ is unsaturated. The evolution of $N_{\mathrm{f}}$ is given by

$$
\frac{\mathrm{d} N_{\mathrm{f}}}{\mathrm{d} t}=\frac{\left(R-R_{\mathrm{i}}\right) \cos \alpha}{\theta\left(R, N_{\mathrm{\digamma}}\right)-\theta\left(R_{\mathrm{i}}, N_{\mathrm{f}}\right)}
$$

which is derived in the Appendix.

The rate of advance of the wetting front depends on the difference between the rainfall rate and the initial

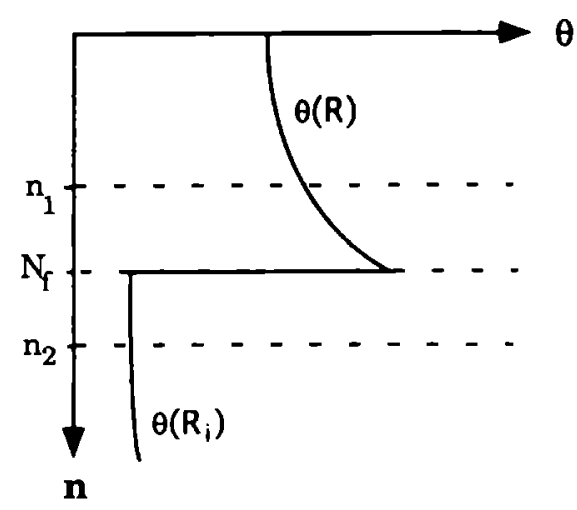

Fig. 5. Wetting front described by the kinematic model of infiltration. Above the wetting front moisture distribution is that corresponding to the rainfall rate $R$, and below the wetting front moisture distribution corresponds to the initital recharge rate $R_{i}$.

recharge rate $\left(R-R_{\mathrm{i}}\right)$ and the difference between the moisture distributions corresponding to $R$ and $R_{\mathrm{i}}$ at the depth of the wetting front. Once the wetting front reaches the critical depth $N^{*}(R)$, soil conductivity will equal the infiltration rate. From that point downwards, the soil can no longer increase its moisture content to keep normal hydraulic conductivity equal to the rainfall rate, and therefore perched saturation develops at and above the wetting front. Flow in this saturated zone is the subject of the next section.

\section{ANALYSIS OF SATURATED FLOW}

The soil column above the wetting front is saturated in two cases: (1) when the rainfall rate is higher than the surface saturated conductivity $\left(R>K_{0_{n}}\right)$, or (2) when the wetting front has penetrated beyond the critical depth $\left(N_{\mathrm{f}} \geq N^{*}(R)\right)$.

In the first case, the entire wetted soil (i.e., from the surface to $N_{f}$ ) is saturated. In the second case, as the front reaches $N^{*}(R)$ infiltration can only be less than recharge from above, and moisture progressively accumulates above the wetting front. A zone of perched saturation develops and grows upward from $N^{*}(R)$, as well as downward as the front progresses. In order to fully descibe the soil moisture profile in this case, it is necessary to specify not only the depth of the wetting front but also the depth of the top of the zone of perched saturation. Therefore, we introduce a new variable $N_{\mathrm{t}}$, defined as $N_{\mathrm{f}}$ minus the height of the zone of perched saturation. If there is a zone of perched saturation, this definition corresponds to the normal distance from the top of the zone of saturation to the soil surface. If the whole wetted soil is unsaturated $\left(N_{\mathrm{f}}<N^{*}(R)\right)$, then $N_{\mathrm{t}}$ equals $N_{\mathrm{f}}$. Equations of evolution for $N_{\mathrm{t}}$ as well as for $N_{\mathrm{f}}$ are derived below. Figure 6 represents the progression of the wetting front in time, showing the development of a zone of saturation and the upward evolution of $N_{\mathrm{r}}$. 

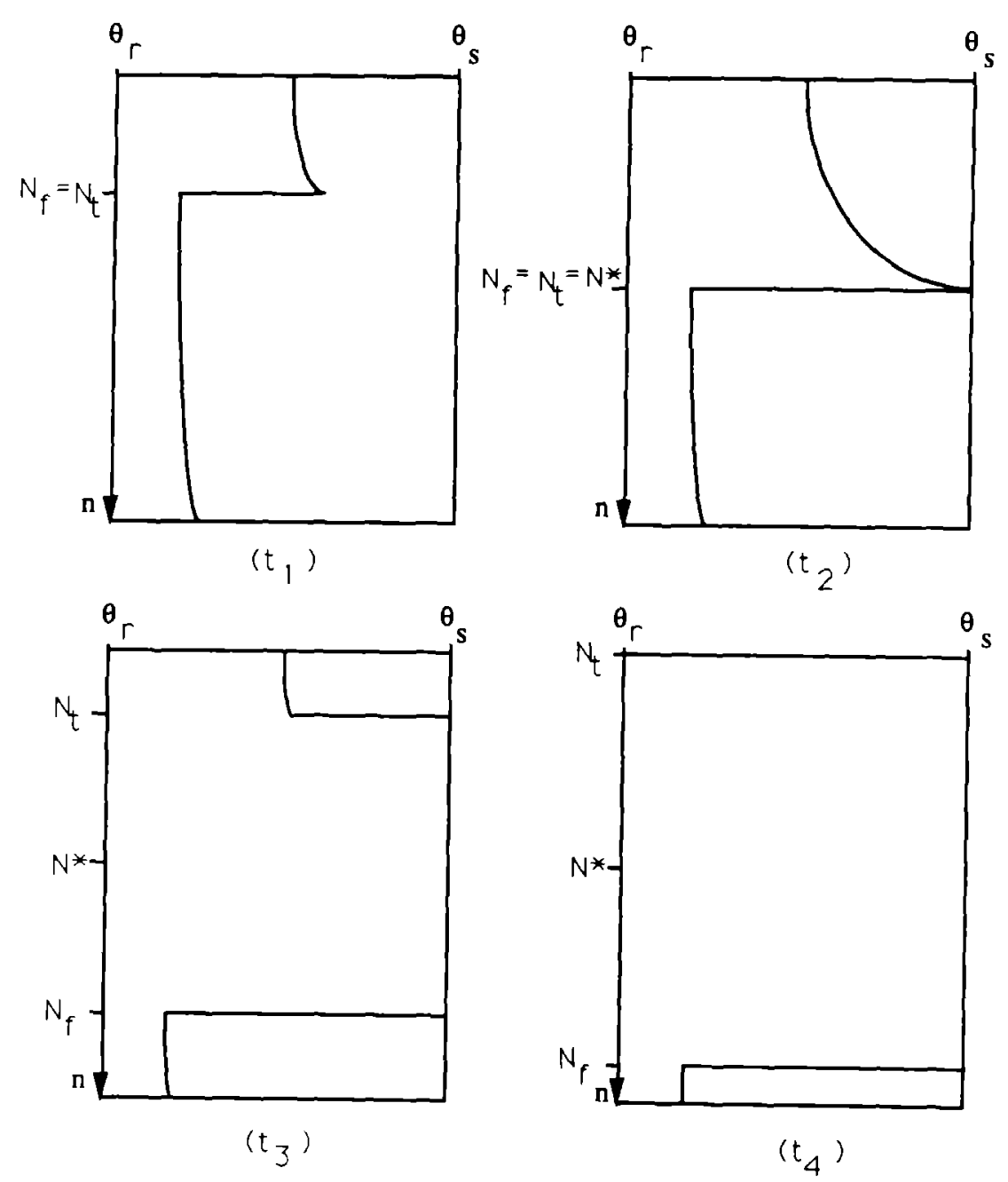

Fig. 6. Evolution of the moisture profile over four consecutive time steps, $t_{1}$ through $t_{4}$, under constant rainfall rate $R$. At time $t_{1}$ the wetting front is still unsaturated. At time $t_{2}, N_{\mathrm{f}}$ reaches the critical depth $N^{*}(R)$ for which we have $K_{\mathrm{s}_{n}}\left(N^{*}\right)=R$. From time $t_{2}$ on, a zone of saturation develops and grows. At time $t_{4}$, the top of the zone of saturation reaches the soil surface, i.e. $N_{\mathrm{t}}=0$.

\subsection{Flow geometry}

The first term in the continuity equation (Al) is zero within the zone of saturation since $\theta(t)=\theta_{\mathrm{s}}$ and the saturated flow is laterally non-divergent. Since we have also assumed that all derivatives in the $p$ direction are zero, the non-divergence of flow translates into

$$
\frac{\partial q_{n}}{\partial n}=0
$$

Equation (22) yields $q_{n}(n)$ as constant in the $n$ direction. Since the elevation gradient is constant and hydraulic conductivity decreases with depth, constant normal flow within the saturated zone implies a positive pressure buildup within it. A pressure gradient compensates for the different hydraulic conductivities of the successive layers of the saturated zone in order to keep normal flow constant. Therefore, the hydraulic gradient within the saturated zone has to account for the gradient of that positive pressure distribution,

$$
\mathbf{J}=J_{n} \mathbf{i}_{n}+J_{p} \mathbf{i}_{p}=\left(-\cos \alpha+\frac{\partial \Psi}{\partial n}\right) \mathbf{i}_{n}-\sin (\alpha) \mathbf{i}_{p}
$$

where scalar $\Psi$ is the positive pore pressure head, which varies only with normal depth alone.

The flow equation in the saturated zone is

$$
\begin{aligned}
\mathbf{q} & =q_{n} \mathbf{i}_{n}+q_{p} \mathbf{i}_{p}=-K_{\mathrm{s}_{n}} J_{n} \mathbf{i}_{n}-K_{\mathrm{s}_{p}} J_{p} \mathbf{i}_{p} \\
& =-K_{0_{n}} \mathrm{e}^{-f n} J_{n} \mathbf{i}_{n}-K_{0_{p}} \mathrm{e}^{-f n} J_{p} \mathbf{i}_{p}
\end{aligned}
$$

Substituting the value of the hydraulic gradient in the $n$ direction $J_{n}$ into the expression for $q_{n}$,

$$
q_{n}(n)=\left(\cos \alpha-\frac{\partial \Psi}{\partial n}\right) K_{0_{n}} \mathrm{e}^{-f_{n}}
$$

Upon substitution of eqn (25) into eqn (22) we obtain the differential equation that governs pressure 
distribution within the saturated zone,

$$
\frac{\partial}{\partial n}\left[\left(\cos \alpha-\frac{\partial \Psi}{\partial n}\right) K_{0_{n}} \mathrm{e}^{-f n}\right]=0
$$

or

$$
\frac{\partial^{2} \Psi}{\partial n^{2}}-f \frac{\partial \Psi}{\partial n}+f \cos \alpha=0
$$

Pressure at both fronts $N_{\mathrm{t}}$ and $N_{\mathrm{f}}$ can be assumed atmospheric given that they are in contact with the unsaturated zones, which have zero pressure according to the kinematic model of infiltration. The area above the top front is directly in contact with the atmosphere. The area below the wetting front can be assumed to be open to atmospheric pressure given the spatial variability in the real moisture distribution at the basin scale. Integration of eqn (26) with the boundary conditions $\Psi\left(N_{\mathrm{f}}\right)=\Psi\left(N_{\mathrm{t}}\right)=0$ leads to

$$
\begin{aligned}
\Psi(n)= & \cos (\alpha)\left[\left(n+\frac{1}{f}\right)-\frac{\mathrm{e}^{f N_{\mathrm{f}}}-\mathrm{e}^{f n}}{\mathrm{e}^{f N_{\mathrm{f}}}-\mathrm{e}^{f N_{\mathrm{t}}}}\left(N_{\mathrm{t}}+\frac{1}{f}\right)\right. \\
& \left.-\frac{\mathrm{e}^{f n}-\mathrm{e}^{f N_{\mathrm{t}}}}{\mathrm{e}^{f N_{\mathrm{f}}}-\mathrm{e}^{f N_{\mathrm{t}}}}\left(N_{\mathrm{f}}+\frac{1}{f}\right)\right]
\end{aligned}
$$

The hydraulic potential can be obtained upon differentiation of the pressure distribution,

$$
\mathbf{J}=-\left(\frac{f\left(N_{\mathrm{f}}-N_{\mathrm{t}}\right)}{\mathrm{e}^{f N_{\mathrm{t}}}-\mathrm{e}^{f N_{\mathrm{t}}}} \mathrm{e}^{f n}\right) \cos (\alpha) \mathbf{i}_{n}-\sin (\alpha) \mathbf{i}_{p}
$$

Substitution of $J_{n}$ in the flow eqn (24) gives the expression for the normal flow in the saturated area,

$$
q_{n}=-K_{0_{n}} \mathrm{e}^{-f n} J_{n}=K_{0_{n}} \frac{f\left(N_{\mathrm{f}}-N_{\mathrm{t}}\right)}{\mathrm{e}^{f N_{\mathrm{f}}}-\mathrm{e}^{f N_{\mathrm{t}}}} \cos \alpha
$$

Normal flow is constant in the saturated area. We can define an 'equivalent hydraulic conductivity' for the saturated area, $K_{\text {eq }}$, as the normal hydraulic conductivity of a homogeneous soil with the same normal flow $q_{n}$ given by eqn (29). The equivalent hydraulic conductivity is given by

$$
K_{\text {eq }}\left(N_{\mathrm{f}}, N_{\mathrm{t}}\right)=K_{0_{n}} \frac{f\left(N_{\mathrm{f}}-N_{\mathrm{t}}\right)}{\mathrm{e}^{f N_{\mathrm{f}}}-\mathrm{e}^{f N_{\mathrm{t}}}}
$$

This equivalent conductivity also corresponds to the harmonic mean of the conductivities over the saturated depth,

$$
K_{\mathrm{eq}}\left(N_{\mathrm{f}}, N_{\mathrm{t}}\right)=\frac{\int_{N_{\mathrm{t}}}^{N_{\mathrm{f}}} \mathrm{d} n}{\int_{N_{\mathrm{t}}}^{N_{\mathrm{f}}} \frac{\mathrm{d} n}{K_{\mathrm{S}_{n}}(n)}}
$$

We may also designate by 'equivalent depth', $N_{\text {eq }}$, the normal depth which has conductivity equal to
$K_{\text {eq }}\left(N_{\mathrm{f}}, N_{\mathrm{t}}\right)$. From eqns (1a) and (30),

$$
N_{\mathrm{eq}}\left(N_{\mathrm{f}}, N_{\mathrm{t}}\right)=-\frac{1}{f} \ln \left[\frac{f\left(N_{\mathrm{f}}-N_{\mathrm{t}}\right)}{\mathrm{e}^{f N_{\mathrm{f}}}-\mathrm{e}^{f N_{\mathrm{t}}}}\right]
$$

$N_{\text {eq }}$ is also the depth at which the pressure distribution (eqn (27)) is maximum, because for that point the pressure gradient is zero and flow is controlled only by the unit gravitational gradient. For depths smaller than $N_{\text {eq }}$, that is $N_{\mathrm{t}}<n<N_{\text {eq }}$, the saturated hydraulic conductivity is greater than $K_{\text {eq }}$, and the pressure gradient is positive (increasing pressure with depth) to compensate for the excess in hydraulic conductivity and to maintain constant normal flow. For depths greater than $N_{\text {eq }}$, that is $N_{\text {eq }}<n<N_{\mathrm{f}}$, the saturated hydraulic conductivity is smaller than $K_{\mathrm{eq}}$, and constant normal flow implies a negative pressure gradient in that area, up to the wetting front, where pressure is again atmospheric.

The parallel component of $\mathbf{J}$ is entirely gravitational, and the flow in this direction is given by

$$
q_{p}=-K_{0_{p}} \mathrm{e}^{-f n} J_{p}=K_{0_{p}} \mathrm{e}^{-f n} \sin \alpha
$$

Within the saturated zone above the wetting front normal flow is constrained by continuity, but parallel flow is not affected by the pressure gradient in the normal direction. As a consequence, flow above the wetting front is deflected laterally. Because conductivity is a function of normal depth $n$, the angle of flow deflection and the components of flow in directions $p$ and $n$ are also functions of $n$. The angle of flow with the vertical direction within the zone of saturation is designated $\beta_{s}(n)$, and is obtained from eqns (29) and (33):

$$
\frac{q_{p}}{q_{n}}=\tan \left(\alpha+\beta_{\mathrm{s}}(n)\right)=a_{\mathrm{r}} \tan (\alpha) \frac{\mathrm{e}^{f N_{\mathrm{f}}}-\mathrm{e}^{f N_{\mathrm{t}}}}{f\left(N_{\mathrm{f}}-N_{\mathrm{l}}\right)} \mathrm{e}^{-f n}
$$

Solving for $\beta_{\mathrm{s}}(n)$,

$$
\beta_{\mathrm{s}}(n)=\tan ^{-1}\left(a_{\mathrm{r}} \tan (\alpha) \frac{\mathrm{e}^{f N_{\mathrm{f}}}-\mathrm{e}^{f N_{\mathrm{t}}}}{f\left(N_{\mathrm{f}}-N_{\mathrm{t}}\right)} \mathrm{e}^{-f n}\right)-\alpha
$$

Flow deflection with respect to the vertical direction in the saturated area is due to two superimposed effects. First, the hydraulic gradient is at an angle $\gamma(n)$, due to its pressure component. The angle $\gamma(n)$ can be obtained from eqn (28):

$$
\frac{J_{p}}{J_{n}}=\tan (\alpha+\gamma(n))=\tan (\alpha) \frac{\mathrm{e}^{f N_{\mathrm{f}}}-\mathrm{e}^{f N_{\mathrm{t}}}}{f\left(N_{\mathrm{f}}-N_{\mathrm{t}}\right)} \mathrm{e}^{-f n}
$$

For depths smaller than $N_{\text {eq }}, N_{\mathrm{t}} \leq n<N_{\text {eq }}, \gamma(n)$ is positive and the hydraulic gradient is deflected downslope, but for depths greater than $N_{\text {eq }}, N_{\text {eq }}<n \leq N_{f}$, $\gamma(n)$ is negative and the gradient is directed into the slope. 
Comparison of eqns (34) and (36) shows that besides the deflection due to the hydraulic gradient, soil anisotropy is a second cause by which flow may be deflected in the saturated zone. Flow is deflected from the direction of the hydraulic gradient towards the direction of higher hydraulic conductivity, that is in the downslope direction. Depending on the values of $f, N_{f}$, $N_{\mathrm{t}}$ and $a_{\mathrm{r}}$, the saturated flow can take different directions. For a given depth $n, \beta_{\mathrm{s}}(n)$ increases with the anisotropy ratio, with the depth of the wetting front and with the thickness of the perched saturation zone. The angle of flow is never larger than $90-\alpha$ (i.e. parallel to the surface), but for small values of $a_{\mathrm{r}}$, it can be negative for some values of $n$ (flow is directed into the slope). For $a_{\mathrm{r}}=1$, that is, for an isotropic soil, flow is directed into the slope for all depths greater than $N_{\text {eq }}$.

\subsection{Vertical and horizontal components of flow}

The vertical and horizontal components of flow are obtained by projecting the flow vector $q$ on the $z$ and $x$ axes. Since there is no variation of front normal depth in the $p$ direction, the values of $N_{\mathrm{f}}$ and $N_{\mathrm{t}}$ are constant for all the hillslope, and therefore independent of vertical depth $z$.

$$
\begin{aligned}
& q_{=}(n)=q_{n} \cos \alpha+q_{p} \sin \alpha \\
& =\left[K_{0_{n}} \frac{f\left(N_{\digamma}-N_{\mathrm{t}}\right)}{\mathrm{e}^{f N_{\mathrm{f}}}-\mathrm{e}^{f N_{\mathrm{t}}}} \cos \alpha\right] \cos \alpha \\
& +\left(K_{0_{p}} \mathrm{e}^{-f n} \sin \alpha\right) \sin \alpha \\
& q_{x}(n)=-q_{n} \sin \alpha+q_{p} \cos \alpha \\
& =-\left[K_{0_{n}} \frac{f\left(N_{\mathrm{f}}-N_{\mathrm{t}}\right)}{\mathrm{e}^{f N_{\mathrm{r}}}-\mathrm{e}^{f N_{\mathrm{t}}}} \cos \alpha\right] \sin \alpha \\
& +\left(K_{0_{p}} \mathrm{e}^{-f n} \sin \alpha\right) \cos \alpha
\end{aligned}
$$

Upon simplification of eqns (37a) and (37b).

$$
\begin{aligned}
q_{z}(z)= & K_{0_{n}}\left[a_{\mathrm{r}} \mathrm{e}^{-f=\cos \alpha} \sin ^{2} \alpha\right. \\
& +\frac{f\left(N_{\mathrm{f}}-N_{\mathrm{t}}\right)}{\left.\mathrm{e}^{f N_{\mathrm{f}}}-\mathrm{e}^{f N_{\mathrm{r}}} \cos ^{2} \alpha\right]} \\
q_{x}(z)= & K_{0_{n}}(\sin \alpha \cos \alpha)\left[a_{\mathrm{r}} \mathrm{e}^{-f_{z} \cos \alpha}\right. \\
& \left.-\frac{f\left(N_{\mathrm{f}}-N_{\mathrm{t}}\right)}{\mathrm{e}^{f N_{\mathrm{f}}}-\mathrm{e}^{f N_{\mathrm{t}}}}\right]
\end{aligned}
$$

As a consequence of flow deflection, vertical infiltration in the saturated zone is not constant with depth. It is the sum of a constant term and a term which decays exponentially with depth. The resulting horizontal flow may be positive or negative (directed in the downslope or upslope direction), depending on the relative values of $a_{\mathrm{r}}, f, N_{\mathrm{f}}$ and $N_{\mathrm{t}}$. Its component directed into the slope is constant with vertical depth $z$, but its component directed out of the slope decreases exponentially with depth.

\subsection{Wetting and top front evolution in saturated infiltration}

As in the case of unsaturated infiltration. detailed in the Appendix, the equation of evolution of $N_{f}$ is obtained through integration of the continuity equation upon substitution of the kinematic flow equation. The domain of integration $\Omega$ is now defined by $N_{\mathrm{t}}<n_{1}<N_{\mathrm{f}}<n_{2}$. Normal flow $q_{n}$ is given by eqn (29) at the level of $n_{1}$ (saturated zone) and by $R_{\mathrm{i}} \cos \alpha$ at the level of $n_{2}$ (initial recharge rate). Integration of the twodimensional continuity eqn (A1) over $\Omega$ gives

$$
\frac{\mathrm{d} N_{\mathrm{f}}}{\mathrm{d} t}=\frac{K_{0_{\mathrm{n}}} \frac{f\left(N_{\mathrm{f}}-N_{\mathrm{t}}\right)}{\mathrm{e}^{f N_{\mathrm{f}}}-\mathrm{e}^{f N_{\mathrm{t}}}-R_{\mathrm{i}}}}{\theta_{\mathrm{s}}-\theta\left(R_{\mathrm{i}}, N_{\mathrm{f}}\right)} \cos \alpha
$$

Derivation of the equation of evolution for $N_{1}$ is entirely analogous to that for $N_{\mathrm{f}}$. The domain of integration is now delimited by $n_{1}$ and $n_{2}$ defined by $n_{1}<N_{1}<n_{2}<N_{f}$. Normal flow is given by eqn (13) at depth $n_{1}$ and by eqn (29) at depth $n_{2}$. Top front evolution is given by

$$
\frac{\mathrm{d} N_{\mathrm{t}}}{\mathrm{d} t}=\frac{K_{0_{n}} \frac{f\left(N_{\mathrm{f}}-N_{\mathrm{t}}\right)}{\mathrm{e}^{f N_{\mathrm{f}}}-\mathrm{e}^{f N_{\mathrm{t}}}-R}}{\theta_{\mathrm{s}}-\theta\left(R, N_{\mathrm{t}}\right)} \cos \alpha
$$

Since we have $R \cos \alpha>q_{n}$ in the saturated zone, the time derivative of $N_{\mathrm{t}}$ is negative, i.e., $N_{\mathrm{t}}$ approaches the terrain surface. Eventually, $N_{\mathrm{t}}$ will reach the surface $\left(N_{\mathrm{t}}=0\right)$, and from then on we must have

$$
N_{\mathrm{t}}=0 ; \quad \frac{\mathrm{d} N_{\mathrm{t}}}{\mathrm{d} t}=0
$$

\section{THE INFILTRATION MODEL}

For $N_{1}=0$, compatibility of eqn (4l) with eqn (40) requires that $R=q_{n}$ in the saturated zone, with $R$ now representing the rate of infiltration. The rate of infiltration is now smaller than the rainfall rate and infiltration excess runoff is generated. This situation also applies to the case $R>K_{0_{n}}$. In the model, the highest saturated hydraulic conductivities are found at the surface. Thus if the rainfall rate is higher than this conductivity value and only kinematic infiltration is considered, then there will be no unsaturated infiltration from the beginning of the storm. The top of the saturated zone is permanently at the surface and wetting front evolution is only governed by eqn (39).

In summary, if we designate the rate of infiltration by 
$R_{\text {inf }}$ and the rate of runoff by $R_{\mathrm{r}}$,

$$
\begin{aligned}
& R_{\mathrm{inf}}= \begin{cases}R \cos \alpha & \text { for } N_{\mathrm{t}}>0 \\
K_{0_{n}} \frac{f N_{\mathrm{f}}}{\left(\mathrm{e}^{f N_{\mathrm{f}}}-1\right)} \cos \alpha & \text { for } N_{\mathrm{t}}=0\end{cases} \\
& R_{\mathrm{r}}=R-R_{\mathrm{inf}}
\end{aligned}
$$

When the top front reaches the surface of the soil, infiltration into the soil is no longer controlled by the infiltration capacity of the upper layer (surface normal hydraulic conductivity $K_{0_{n}}$ ), but by the infiltration capacity of the whole saturated profile, equal to the equivalent hydraulic conductivity $K_{\text {eq }}$ (harmonic mean of the hydraulic conductivities of the saturated zone). Since for a constant rainfall rate $R$ the saturated area is expanding, the infiltration capacity of the saturated area decreases in time.

\section{LATERAL SUBSURFACE DISCHARGE FROM A VERTICAL CROSS-SECTION}

In this section we obtain an expression for the lateral discharge from a vertical cross-section of the hillslope soil. The total discharge from the wetted soil, represented by $Q$, from a vertical cross-section of width $W$ is obtained through integration over the wetted depth (i.e. from 0 to $N_{\digamma} / \cos \alpha$ ) of the horizontal component of flow,

$$
Q=W \int_{0}^{N_{\mathrm{f}} / \cos \alpha} q_{x}(z) \mathrm{d} z
$$

Replacing this integral by its components within the unsaturated and saturated zones,

$$
Q=W\left[\int_{0}^{N_{\mathrm{f}} / \cos \alpha} q_{x}(z) \mathrm{d} z+\int_{N_{\mathrm{l}} / \cos \alpha}^{N_{\mathrm{f}} / \cos \alpha} q_{x}(z) \mathrm{d} z\right]
$$

Substituting eqns (20b) and (38b) in the first and second integrals of eqn (45), respectively, we obtain

$$
\begin{aligned}
Q= & W \sin \alpha\left\{\left[N_{\mathrm{t}} R\left(a_{\mathrm{r}}-1\right)\right]\right. \\
& +\left[K_{0_{n}} \frac{a_{\mathrm{r}}}{f}\left(\mathrm{e}^{-f N_{\mathrm{t}}}-\mathrm{e}^{-f N_{\mathrm{f}}}\right)\right] \\
& \left.-\left[K_{0_{n}} \frac{f\left(N_{\mathrm{f}}-N_{\mathrm{t}}\right)^{2}}{\mathrm{e}^{f N_{\mathrm{f}}}-\mathrm{e}^{f N_{\mathrm{t}}}}\right]\right\}
\end{aligned}
$$

For a rainfall rate lower than the initial infiltration capacity, i.e. for $R<K_{0_{n}}$, lateral discharge is given by the first square bracketed term of eqn (46) while we have $N_{\mathrm{t}}=N_{\mathrm{f}}<N^{*}(R)$. In this case, lateral discharge increases with the anisotropy ratio. After perched saturation has developed, i.e. for $N_{\mathrm{t}}<N^{*}(R)<N_{\mathrm{f}}$, lateral discharge is given by all three terms of eqn (46) while we have $N_{1}>0$. In the advanced stages of
Table 1. Numerical values used in the simulations

\begin{tabular}{lrrrrrr} 
& \multicolumn{5}{c}{ Reference values } \\
\hline Rainfall rate $(\mathrm{mm} / \mathrm{h})$ & 2 & 5 & 7 & 10 & & \\
Slope angle $(\mathrm{c})$ & & 0 & 10 & 20 & 45 & \\
Anisotropy ratio & 1 & 5 & 10 & 100 & \\
Parameter $f\left(\mathrm{~m}^{-1}\right)$ & & & 10 & 5 & 1 & $0 \cdot 1$ \\
\hline
\end{tabular}

infiltration, we have $N_{\mathrm{t}}=0$ and $N_{\mathrm{f}}$ very large. Therefore, the first term in eqn (46) equals zero, the third approaches zero, and the second term has a limit value for large $N_{\mathrm{f}}$ given by

$$
\lim _{t \rightarrow \infty} Q=W \sin (\alpha) K_{0_{n}} \frac{a_{\mathrm{r}}}{f}
$$

The limit value increases with the anisotropy ratio and the surface saturated hydraulic conductivity and decreases with the rate of conductivity decay, $f$, with depth.

\section{INFILTRATION MODEL SENSITIVITIES}

We present model results for various soil parameter values, rainfall rates, and terrain inclinations. A soil with the following basic characteristics was selected to obtain numerical results:

$$
\begin{aligned}
K_{0_{n}} & : 20 \mathrm{~mm} / \mathrm{h} \\
\theta_{\mathrm{s}} & : 0.5 \\
\theta_{\ulcorner} & : 0.05 \\
\epsilon & : 4.0
\end{aligned}
$$

The soil is assumed to be almost dry at the beginning of the event. An initial recharge rate of $R_{\mathrm{i}}=0.01 \mathrm{~mm} / \mathrm{h}$ defines this initial moisture distribution.

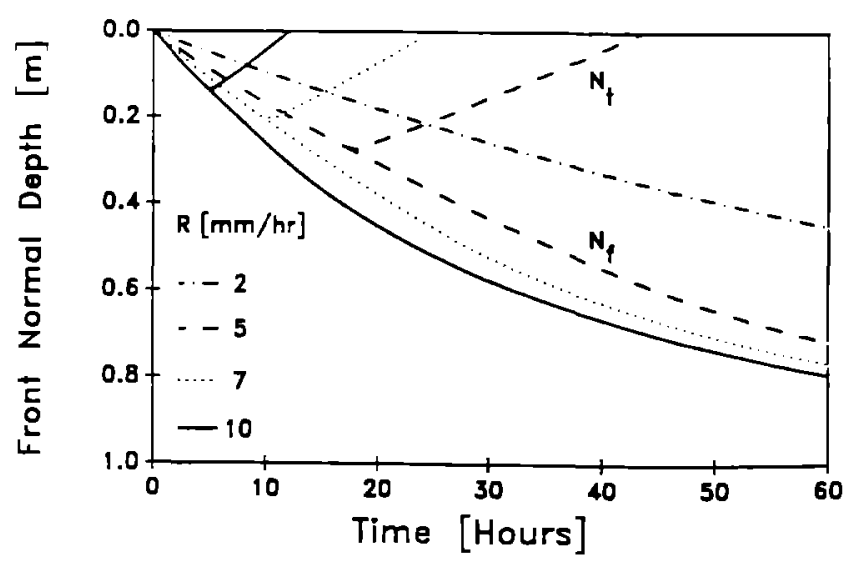

Fig. 7. Front position as a function of time for different rainfall intensities. The slope angle is $20^{\circ}$. Normal hydraulic conductivity at the surface is $20 \mathrm{~mm} / \mathrm{h}$, with an exponential decay rate of $5 \mathrm{~m}^{-1}$. The soil is anisotropic, with an anisotropy ratio of 10 . During the unsaturated phase of infiltration both fronts coincide for each case. Once saturation has been reached, the wetting front and the top front diverge as the saturated area grows. 


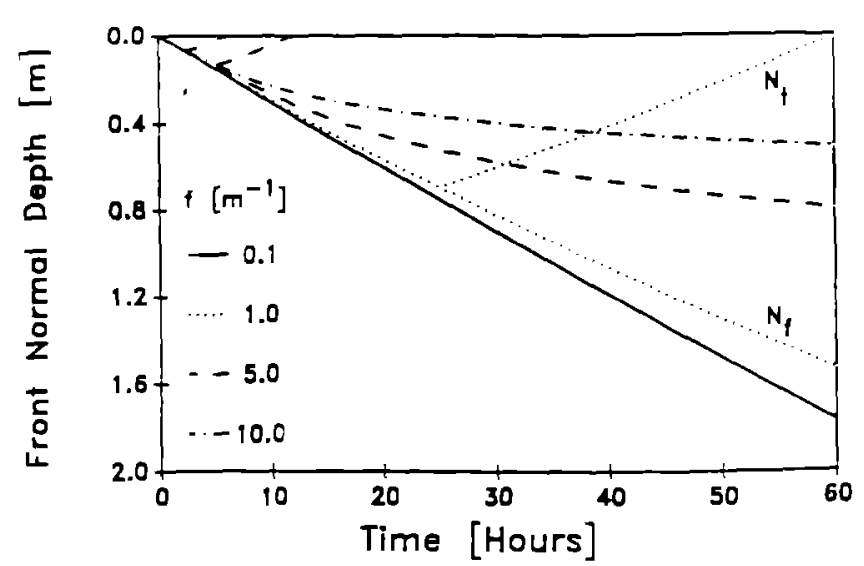

Fig. 8. Front position as a function of time for different values of the exponential decay rate of hydraulic conductivity (parameter $f$ ). Normal hydraulic conductivity at the surface is $20 \mathrm{~mm} / \mathrm{h}$, the rainfall intensity is $10 \mathrm{~mm} / \mathrm{h}$, the slope angle is $20^{\circ}$ and the anisotropy ratio is 10 .

Sensitivity analyses were carried out for the other variables affecting the results, namely rainfall rate $(R)$, terrain slope angle $(\alpha)$, anisotropy ratio $\left(a_{\mathrm{r}}\right)$ and decrease of permeability with depth (parameter $f$ ). Table I shows the numerical values adopted for the variables in the sensitivity analysis. A basic set of values (central column) was adopted as a reference. Sensitivity analyses were performed changing only one variable at a time, setting the rest to their basic reference values. The model basically involves the numerical integration of the evolution eqns (21), (39), and (40) for a period equal to $60 \mathrm{~h}$.

Figures 7 to 9 show the position of both the wetting front and the top of the zone of perched saturation for a variety of rainfall rates, $f$-values and slopes. The top front is shown to often diverge from the bottom front, indicating the development and growth of a zone of perched saturation. Figure 7 shows the evolution in time

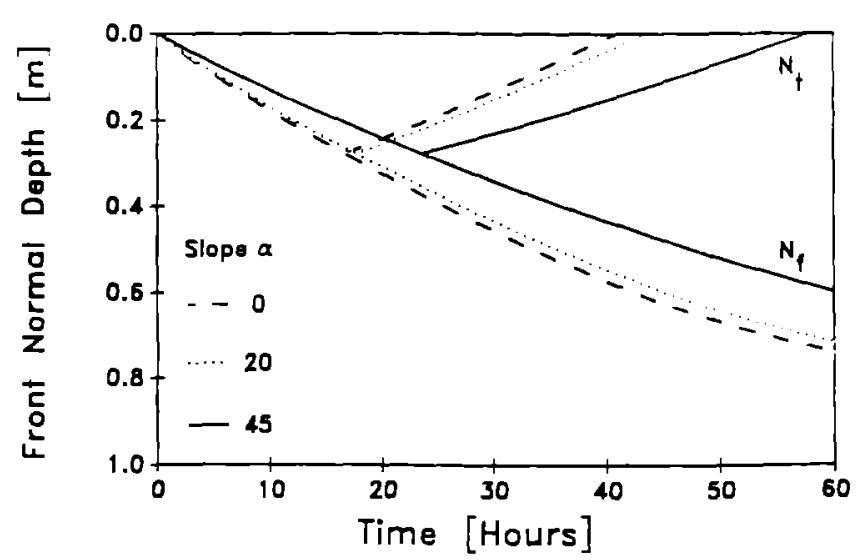

Fig. 9. Front position as a function of time for different slope angles. Rainfall intensity is $5 \mathrm{~mm} / \mathrm{h}$, normal hydraulic conductivity at the surface is $20 \mathrm{~mm} / \mathrm{h}$, the exponential decay rate is $5 \mathrm{~m}^{-1}$ and the anisotropy ratio is 10 .

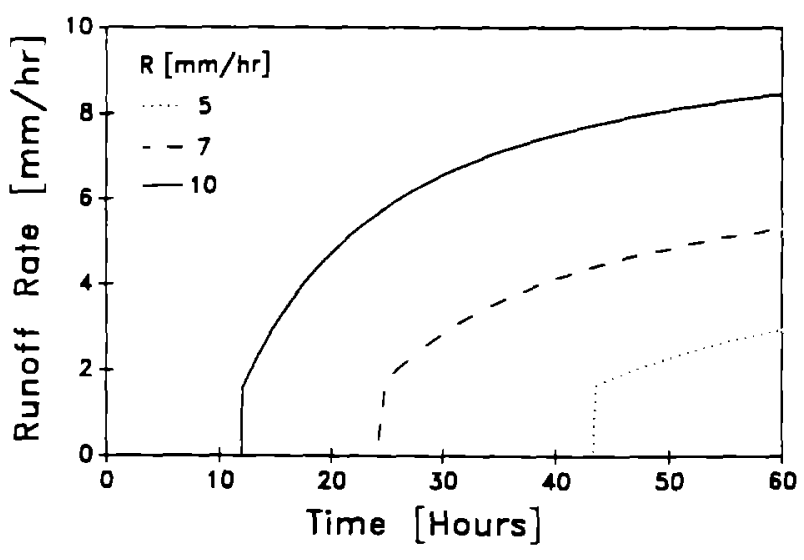

Fig. 10. Hillslope runoff generation as a function of time for different rainfall intensities. The slope angle is $20^{\circ}$, normal hydraulic conductivity at the surface is $20 \mathrm{~mm} / \mathrm{h}$, the exponential decay rate is $5 \mathrm{~m}^{-1}$ and the soil is anisotropic. with an anisotropy ratio of 10 .

of front depth for different rainfall intensities. It can be seen that except for the case with lowest rainfall intensity, saturation is reached at a relatively shallow position. Figure 8 shows the importance of parameter $f$ for the definition of the depth $N^{*}$. and consequently in the position of the fronts and evolution of the saturated area. Figure 9 shows that the sensitivity to the slope angle $\alpha$ is small except for steep inclinations. There is no sensitivity analysis to the anisotropy ratio because front evolution (and therefore front position) is independent of soil anisotropy parallel to the soil surface.

Figures 10 to 12 show the effect of model parameters in the generation of hillslope runoff. All rainfall intensities used in Fig. 10 are smaller than the surface normal saturated conductivity $(20 \mathrm{~mm} / \mathrm{h})$. In three cases, hillslope runoff is generated during the first $60 \mathrm{~h}$ of storm in a relatively dry soil. At the beginning of the

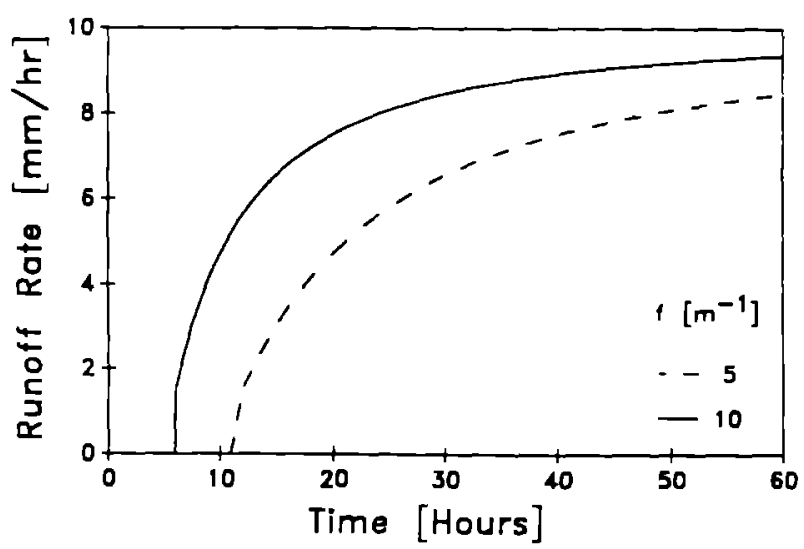

Fig. 11. Hillslope runoff generation as a function of time for different values of the exponential decay rate of hydraulic conductivity (parameter $f$ ). Normal hydraulic conductivity at the surface is $20 \mathrm{~mm} / \mathrm{h}$, the rainfall intensity is $10 \mathrm{~mm} / \mathrm{h}$, the slope angle is $20^{\circ}$ and the anisotropy ratio is 10 . 


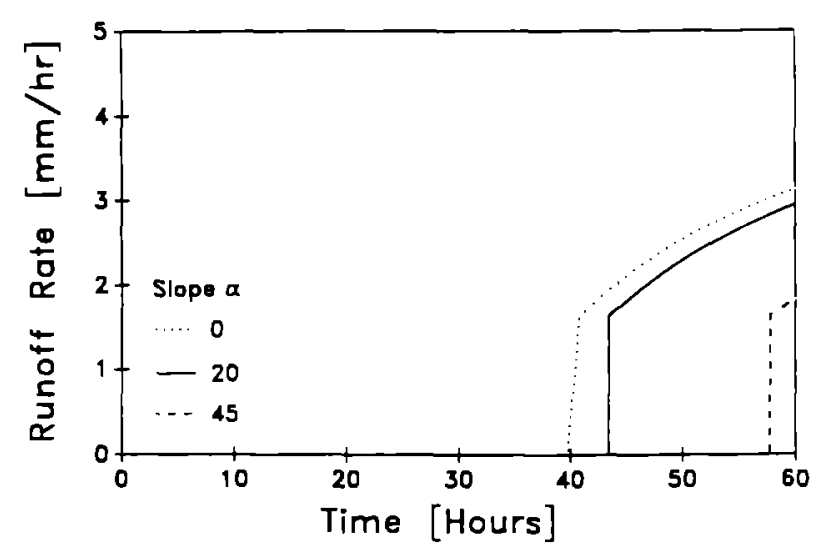

Fig. 12. Hillslope runoff generation as a function of time for different slope angles. Rainfall density is $5 \mathrm{~mm} / \mathrm{h}$, normal hydraulic conductivity at the surface is $20 \mathrm{~mm} / \mathrm{h}$, the exponential decay rate is $5 \mathrm{~m}^{-1}$ and the anisotropy ratio is 10 .

event, the infiltration rate is equal to rainfall intensity because the process is controlled by the infiltration capacity of the unsaturated upper layers of the soil. When the top front reaches the surface, infiltration is controlled by the equivalent permeability of the saturated area. That produces a sharp decrease in the infiltration capacity of the soil and the consequent increase in the runoff. From that point on, runoff generation is controlled by the equivalent permeability of the saturated area, which decreases as the wetting front advances further into the soil. Figures 11 and 12 show the sensitivity of runoff generation to the conductivity parameter $f$ and to the slope angle, with similar effects to those already commented for the front evolution.

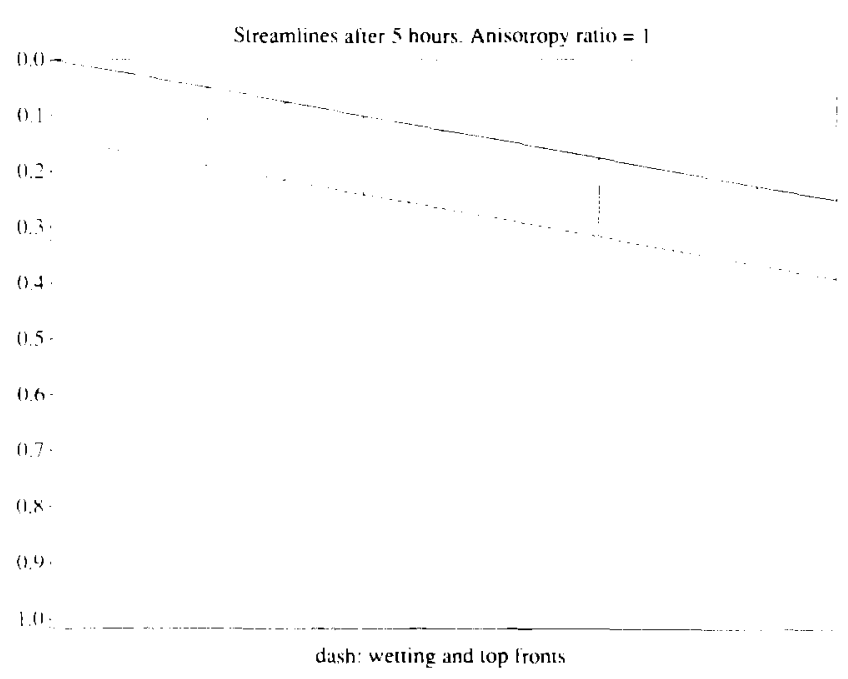

Fig. 13. Representation of flow lines after $5 \mathrm{~h}$ of infiltration for an isotropic soil with slope angle of $10^{\circ}$. Normal hydraulic conductivity at the surface is $20 \mathrm{~mm} / \mathrm{h}$, the exponential decay rate is $5 \mathrm{~m}^{-1}$ and the rainfall intensity is $10 \mathrm{~mm} / \mathrm{h}$. Since the wetted profile is unsaturated, infiltration is in the vertical direction.

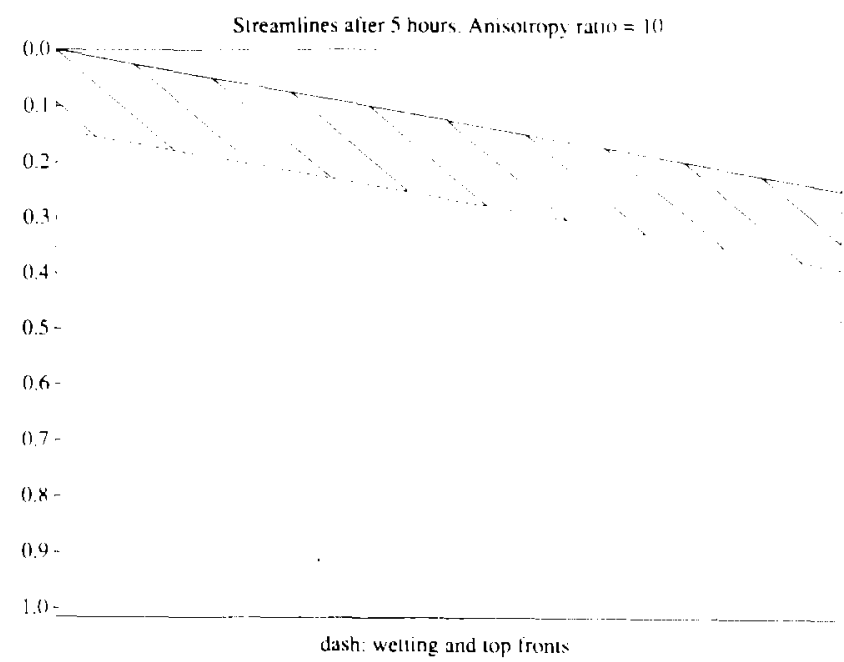

Fig. 14. Representation of flow lines after $5 \mathrm{~h}$ of infiltration for a soil with slope angle of $10^{\circ}$ and anisotropy ratio of 10 . The normal hydraulic conductivity at the surface is $20 \mathrm{~mm} / \mathrm{h}$, the exponential decay rate is $5 \mathrm{~m}^{-1}$ and the rainfall intensity is $10 \mathrm{~mm} / \mathrm{h}$. Since the wetted profile is unsaturated, flow deviation with respect to the vertical, given by eqn (8), is due to the anisotropy.

Figures 13 to 18 show streamlines at different stages of front evolution for soils with anisotropy ratios of 1 and 10 . Figures 13 and 14 correspond to front positions after $5 \mathrm{~h}$ of rainfall. Most of the wetted area is unsaturated and therefore streamlines are vertical lines for the case $a_{\mathrm{r}}=1$ and at an angle $\beta_{\mathrm{u}}=\tan ^{-1}$ $\left[10 \tan \left(10^{\circ}\right)\right]-10^{\circ}$ for the case $a_{\mathrm{r}}=10$. Figures 15 and 16 show the streamlines after $10 \mathrm{~h}$ of rainfall, when the top front is almost at the surface and most of the wetted

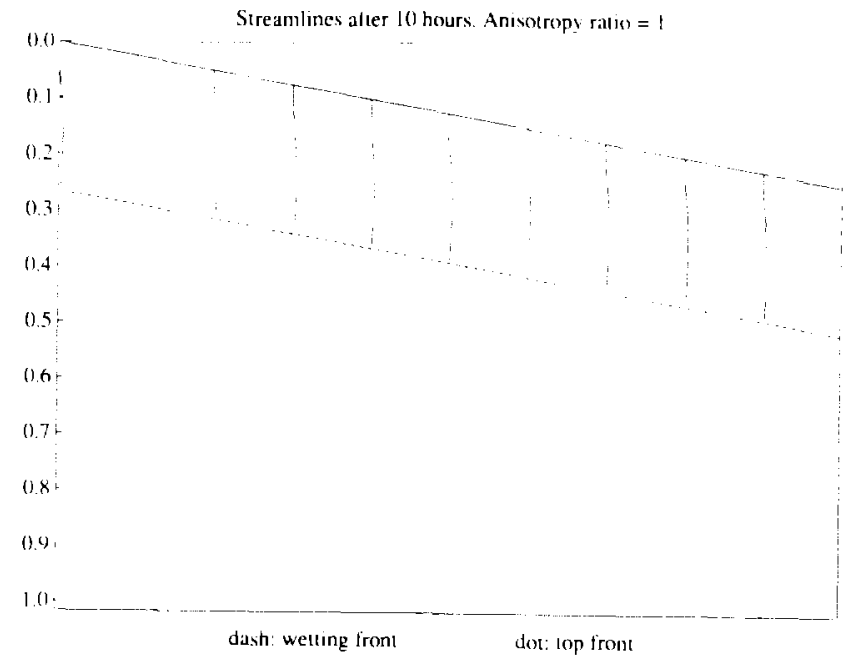

Fig. 15. Representation of flow lines after $10 \mathrm{~h}$ of infiltration for an isotropic soil with slope angle of $10^{\circ}$. The normal hydraulic conductivity at the surface is $20 \mathrm{~mm} / \mathrm{h}$, the exponential decay rate is $5 \mathrm{~m}^{-1}$ and the rainfall intensity is $10 \mathrm{~mm} / \mathrm{h}$. The area of perched saturation has grown and the top front is close to the surface. The streamlines are slightly curved in the saturated area. 


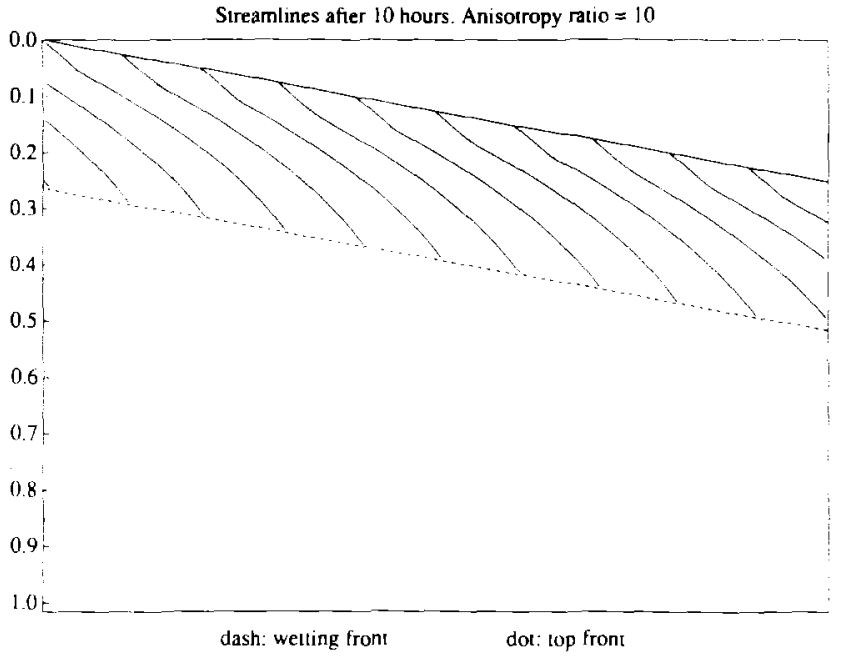

Fig. 16. Representation of flow lines after $10 \mathrm{~h}$ of infiltration for a soil with slope angle of $10^{\circ}$ and anisotropy ratio of 10 . The normal hydraulic conductivity at the surface is $20 \mathrm{~mm} / \mathrm{h}$, the exponential decay rate is $5 \mathrm{~m}^{-1}$ and the rainfall intensity is $10 \mathrm{~mm} / \mathrm{h}$.

area is saturated. Since the saturated area is still relatively shallow the curvature of the streamlines is not large, especially for the case $a_{\mathrm{r}}=1$. Figures 17 and 18 show the streamlines after $60 \mathrm{~h}$ of rainfall, with the entire wetted profile (up to the wetting front) saturated. As is shown in Fig. 17 (isotropic case), soil heterogeneity translates into an overall downslope deviation of flow, although flow in the lower part of the saturated area is directed into the slope. Figure 18 illustrates how anisotropy affects the direction of flow. After many hours of rainfall, flow in the upper part of the saturated

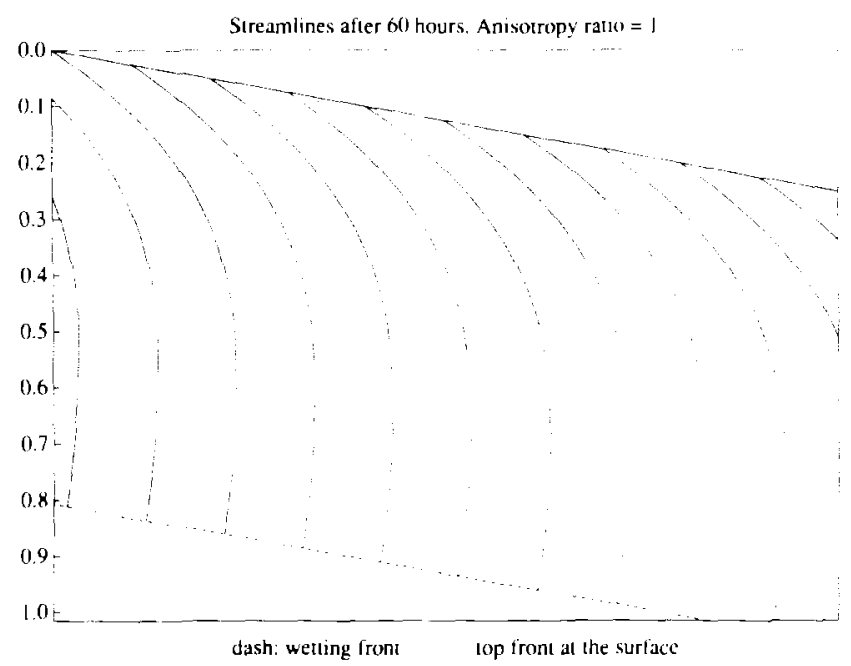

Fig. 17. Representation of flow lines after $60 \mathrm{~h}$ of infiltration for an isotropic soil with slope angle of $10^{\circ}$. The normal hydraulic conductivity at the surface is $20 \mathrm{~mm} / \mathrm{h}$, the exponential decay rate is $5 \mathrm{~m}^{-1}$ and the rainfall intensity is $10 \mathrm{~mm} / \mathrm{h}$. All the wetted profile is saturated. The net effect of the decrease of permeability with depth is an overall deviation of flow in the downslope direction.

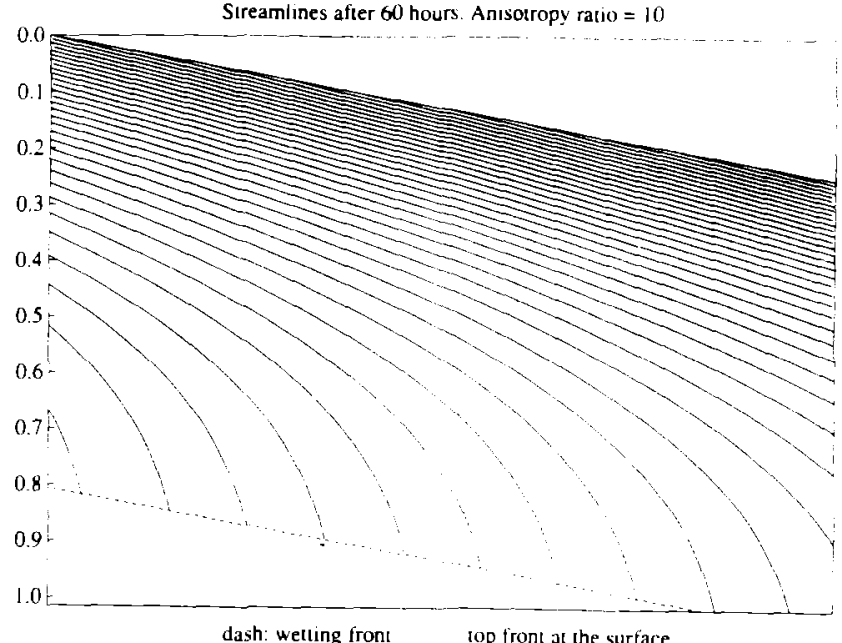

Fig. 18. Representation of flow lines after $60 \mathrm{~h}$ of infiltration for a soil with slope angle of $10^{\circ}$ and anisotropy ratio of 10 . The normal hydraulic conductivity at the surface is $20 \mathrm{~mm} / \mathrm{h}$, the exponential decay rate is $5 \mathrm{~m}^{-1}$ and the rainfall intensity is $10 \mathrm{~mm} / \mathrm{h}$. All the wetted profile is saturated. The combined effect of anisotropy and the decrease of permeability with depth result in an overall deviation of fow, making flow in the downslope direction several times greater than that in the normal direction.

area is almost parallel to the surface, and therefore parallel flow dominates over vertical flow. These results are consistent with field observations of subsurface storm runoff generation ${ }^{12}$ that link storm runoff mostly to the movement of shallow groundwater parallel to the surface. This phenomenon is usually attributed in the literature to macropore flow, but it can be to some extent represented by Darcian matrix flow with a high anisotropy ratio.

\section{CONCLUSIONS}

A model that describes the two-dimensional features of infiltration and subsurface lateral flows considering the effects of anisotropy and vertical heterogeneity has been presented. The model is based on the kinematic approximation and on a simplified mathematical description of soil anisotropy and heterogeneity which allow for analytical treatment of the problem. The key results of this model are the evolution equations for the advance of the wetting front, the lateral subsurface flows and the growth of the zone of perched saturation. The latter evolution equation is a critical component for distributed rainfall-runoff models because it captures the dynamic changes in partial-area runoff contribution during storm events.

The kinematic appproximation leads to the formation of a sharp wetting front. With hydraulic conductivity decreasing with depth, prolonged infiltration leads to the development of saturation at a depth in the soil profile 
where infiltration capacity equals the percolation rate. As the wetting front progresses further below this critical depth, discharge is limited by the lower conductivity at the wetting front and moisture progressively accumulates within a zone of perched saturation. Evolution equations for the location of the wetting front and the growth of the zone of perched saturation have been derived.

The effect of soil heterogeneity and anisotropy on infiltration is flow deflection in the downslope direction. Flow deviation with respect to the vertical has been analyzed for both unsaturated and saturated regimes. Numerical results have been presented to illustrate how this model can reproduce some of the observed twodimensional effects of subsurface stormflow generation in sloped soils.

The most attractive feature of the model presented here is its computational efficiency, since simple analytical expressions for front advance have been derived. However, the simplifying assumptions affect model results in several ways. If capillary forces had not been neglected, (1) diffusive processes would have smoothed out the sharpness of the fronts, (2) the initial infiltration rate would have been lower, and (3) the influence of capillary gradient would have led to a different equilibrium moisture profile. Nevertheless, as a first-order approximation, the infiltration model can be used as the basis for estimating local runoff generation in a distributed basin model. The expression for horizontal flow in a vertical cross-section allows for horizontal flow transfer between the distributed elements. Further reports will focus on the adaptation of the model to variable rainfall rates and to address the problem of the variability in the parallel direction.

\section{ACKNOWLEDGEMENTS}

This research was partially supported by the Arno Project of the National Research Council of Italy, through a cooperative agreement with the University of Florence, Italy. Other sponsors included the US Army Research Office (Grant DAALO-3-89-K-0151), the National Science Foundation (Grant CES-8815725) and the National Weather Service (cooperative agreement NA86AA-D-HY123). Luis Garrote was sponsored by the Spanish Ministry of Education and Science. The contributions of David Tarboton to initial model development are gratefully acknowledged.

\section{REFERENCES}

1. Beven, K. On subsurface stormflow: predictions with simple kinematic theory for saturated and unsaturated flows. Water Resources Research, 1982a, 18(6), 1627-33.

2. Beven, K. On subsurface stormflow: an analysis of response times. Hydrol. Sci. J., 1982b, 4, 505-21.
3. Beven, $\mathbf{K}$. Infiltration into a class of vertically non-uniform soils. Hydrol. Sci. J., 1984, 29, 425-34.

4. Brooks, R.H. \& Corey, A.T. Hydraulic properties of porous media. Hydrology Paper 3, Colorado State University, Fort Collins, CO, 1964.

5. Charbeneau, R.J. Kinematic models for soil moisture and solute transport. Water Resources Research, 1984, 20(6). 699-706.

6. Clapp, R.B. \& Hornberger, G.M. Empirical equations for some soil hydraulic properties. Water Resources Research, $1978,14(4), 601-4$.

7. Dagan, G. \& Bressler, E. Unsaturated flow in spatially variable fields. 1 . Derivation of models of infiltration and redistribution. Water Resources Research, 1983, 19(2), 413-20.

8. McCord, J.T. \& Stephens, D.B. Lateral moisture flow beneath a sandy hillslope without an apparent impending layer. Hydrol. Process. J., 1987, 1, 225-38.

9. Mualem, Y. Hydraulic conductivity of unsaturated porous media: generalized macroscopic approach Water Resources Research, 1978, 14(2), 325-34.

10. Philip. J.R. Hillslope infiltration: planar slopes. Water Resources Research, 1991, 27(1), 109-17.

11. Smith, R.E. \& Hebbert, R.H.B. Mathematical simulation of interdependent surface and subsurface hydrologic processes. Water Resources Research, 1983, 19(4), 987-1001.

12. Tanaka, T., Yashuhara, M., Sakai, H. \& Marui, A. The Hachioji experimental basin study - storm runof processes and the mechanisms of its generation. J. Hydrology, $1988,102,139-64$

13. Yeh, T.C.J., Gelhar, L.W. \& Gutjahr, A.L. Stochastic analysis of unsaturated flow in heterogeneous soils. 1. Statistically isotropic media. Water Resources Research, 1985, 21(4), 447-56.

14. Zaslavsky, D. \& Rogowski, A.S. Hydrologic and morphologic implications of anisotropy and infiltration in soil profile development. Soil Sci. Soc. Amer. Proc., 1969, 33, 594-9.

15. Zaslavsky, D. \& Sinai, G. Surface hydrology: IV - Flow in sloping, layered soil. J. Hydraul. Div., Proc. ASCE, n. HY 1, 1981, 107, 53-64.

\section{APPENDIX}

In this Appendix the equation for the time evolution of the wetting front is derived. The continuity equation in the $(n, p)$ coordinate system is

$$
\frac{\partial \theta}{\partial t}+\frac{\partial q_{n}}{\partial n}+\frac{\partial q_{p}}{\partial p}=0
$$

Equation (A1) can be integrated in the domain $\Omega$ that includes the wetting front (see Fig. Al). Domain $\Omega$ is delineated by the planes $p=p_{1}, p=p_{2}, n=n_{1}$ and $n=n_{2}$, with $n_{1}<N_{\mathrm{f}}<n_{2}$. Integration of the continuity equation in the domain $\Omega$ gives

$$
\begin{aligned}
\int_{\Omega}\left(\frac{\partial \theta}{\partial t}+\frac{\partial q_{n}}{\partial n}+\frac{\partial q_{p}}{\partial p}\right) \mathrm{d} \Omega= & \int_{\Omega}\left(\frac{\partial \theta}{\partial t}\right) \mathrm{d} \Omega \\
& +\int_{\Omega}\left(\frac{\partial q_{n}}{\partial n}+\frac{\partial q_{p}}{\partial p}\right) \mathrm{d} \Omega=0
\end{aligned}
$$

Interchanging the integral and the derivative in the first 


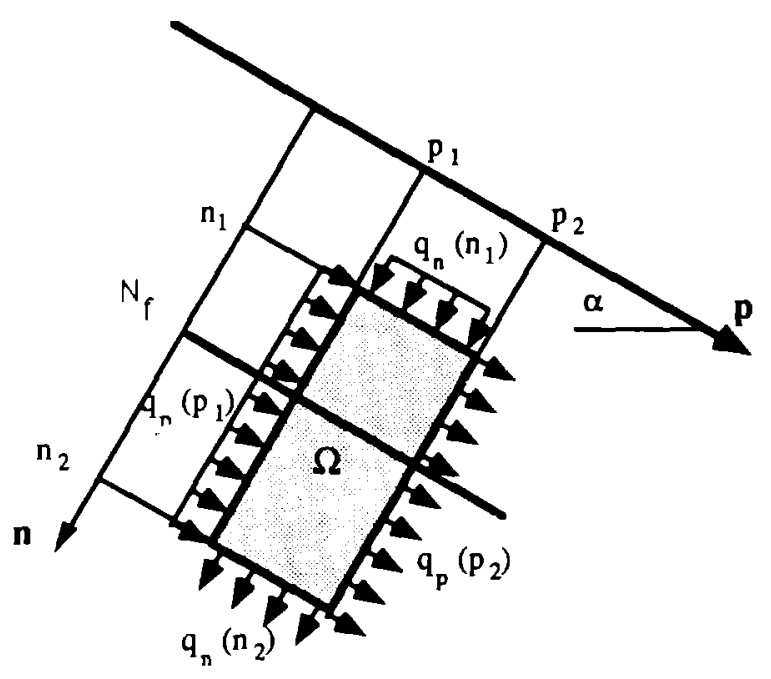

Fig. A1. Integration domain $\Omega$ for the continuity equation. The wetting front $N_{f}$ is between $n_{1}$ and $n_{2}$.

term and applying Green's theorem to the second term gives

$$
\frac{\mathrm{d}}{\mathrm{d} t}\left(\int_{\Omega} \theta \mathrm{d} \Omega\right)+\int_{\partial \Omega}\left(\overrightarrow{\mathbf{q}} \cdot \overrightarrow{\mathbf{i}}_{\mathrm{N}}\right) \mathrm{d} \partial \Omega=0
$$

where $\mathbf{i}_{\mathrm{N}}$ is a unit vector normal to the boundary of $\Omega, \delta \Omega$. The time rate of change in moisture content within $\Omega$ is balanced by the flux of $\mathbf{q}$ across its encompassing boundary $\delta \Omega$.

The soil moisture profile is given by eqn (15). The rainfall rate is $R$ above the wetting front $\left(n_{1}<n<N_{f}\right)$. Prior to the initiation of rainfall the soil moisture profile can be described by a flow rate $R_{\mathrm{i}}<R$. Therefore, the initial moisture profile is given by eqn (15) upon substitution of $R$ by $R_{1}$ for depths below $N_{f}\left(N_{\digamma}<n<n_{2}\right)$, a region still unaffected by the moisture wave. Upon substitution of the soil moisture profile in the integral of the first term of eqn (A3),

$$
\begin{aligned}
\int_{\Omega} \theta \mathrm{d} \Omega= & \int_{p_{1}}^{p_{2}} \int_{n_{1}}^{n_{2}} \theta(n) \mathrm{d} n \mathrm{~d} p=\left(p_{2}-p_{1}\right) \\
& \times\left[\int_{n_{1}}^{N_{\mathrm{f}}} \theta(n) \mathrm{d} n+\int_{N_{\mathrm{f}}}^{n_{2}} \theta(n) \mathrm{d} n\right] \\
= & \left(p_{2}-p_{1}\right)\left[\left(\frac{R}{K_{0_{n}}}\right)^{1 / \epsilon}\left(\theta_{\mathrm{s}}-\theta_{\mathrm{r}}\right)\left(\frac{\epsilon}{f}\right)\right. \\
& \times\left(\mathrm{e}^{f N_{\mathrm{r}} / \epsilon}-\mathrm{e}^{f n_{1} / \epsilon}\right)+\theta_{\mathrm{r}}\left(N_{\mathrm{f}}-n_{1}\right) \\
& +\left(\frac{R_{\mathrm{i}}}{K_{0_{n}}}\right)^{1 / \epsilon}\left(\theta_{\mathrm{s}}-\theta_{\mathrm{r}}\right)\left(\frac{\epsilon}{f}\right) \\
& \left.\times\left(\mathrm{e}^{f n_{2} / \epsilon}-\mathrm{e}^{f N_{\mathrm{r}} / \epsilon}\right)+\theta_{\mathrm{r}}\left(n_{2}-N_{\mathrm{r}}\right)\right]
\end{aligned}
$$

Differentiation of eqn (A4) with respect to time yields the first term in eqn (A3):

$$
\begin{aligned}
\frac{\mathrm{d}}{\mathrm{d} t}\left(\int_{\Omega} \theta \mathrm{d} \Omega\right)= & \left(p_{2}-p_{1}\right)\left\{\left[\left(\frac{R}{K_{0_{n}}}\right)^{1 / \epsilon}\left(\theta_{\mathrm{s}}-\theta_{\mathrm{r}}\right)\right.\right. \\
& \left.\times \mathrm{e}^{f N_{\mathrm{r}} / \epsilon}+\theta_{\mathrm{r}}\right]-\left[\left(\frac{R_{\mathrm{i}}}{K_{0_{\mathrm{n}}}}\right)^{1 / \epsilon}\right. \\
& \left.\left.\times\left(\theta_{\mathrm{s}}-\theta_{\mathrm{r}}\right) \mathrm{e}^{f N_{\mathrm{r}} / \epsilon}+\theta_{\mathrm{r}}\right]\right\} \frac{\mathrm{d} N_{\mathrm{f}}}{\mathrm{d} t}
\end{aligned}
$$

Recalling the expression for $\theta(R, n)$ given by eqn (15),

$$
\begin{aligned}
\frac{\mathrm{d}}{\mathrm{d} t}\left(\int_{\Omega} \theta \mathrm{d} \Omega\right)= & \left(p_{2}-p_{1}\right)\left[\theta\left(R, N_{\mathrm{f}}\right)\right. \\
& \left.-\theta\left(R_{\mathrm{i}}, N_{\mathrm{f}}\right)\right] \frac{\mathrm{d} N_{\mathrm{f}}}{\mathrm{d} t}
\end{aligned}
$$

The second term of eqn (A3) is the flux of the vector $q$ across the boundary of $\Omega$, which leads to

$$
\begin{aligned}
\int_{\partial \Omega}\left(\mathbf{q} \cdot \mathbf{i}_{\mathrm{N}}\right) \mathrm{d} \partial \Omega= & -\left.\int_{n_{1}}^{n_{2}} q_{p}\right|_{p=p_{2}} \mathrm{~d} n-\left.\int_{p_{1}}^{p_{2}} q_{n}\right|_{n=n_{1}} \mathrm{~d} p \\
& +\left.\int_{n_{1}}^{n_{2}} q_{p}\right|_{p=p_{2}} \mathrm{~d} n+\left.\int_{p_{1}}^{n_{2}} q_{n}\right|_{n=n_{2}} \mathrm{~d} p
\end{aligned}
$$

Since the rate of flow parallel to the hillslope is constant with depth

$$
\left.q_{p}\right|_{p=p_{1}}=\left.q_{p}\right|_{p=p_{2}} \quad \forall n
$$

and

$$
\int_{\partial \Omega}\left(\mathbf{q} \cdot \mathbf{i}_{\mathrm{N}}\right) \mathrm{d} \partial \Omega=-\left.\int_{p_{1}}^{p_{2}} q_{n}\right|_{n=n_{1}} \mathrm{~d} p+\left.\int_{p_{1}}^{p_{2}} q_{n}\right|_{n=n_{2}} \mathrm{~d} p
$$

For all depths above the wetting front $\left(n<N_{\mathrm{f}}\right), q_{n}$ is a function of $R$, given by eqn (13). Below the wetting front $\left(n>N_{\mathrm{f}}\right) q_{n}$ is also given by eqn (13), substituting $R$ by $R_{\mathrm{i}}$. It then follows that the terms of eqn (A8) are

$$
\begin{aligned}
-\left.\int_{p_{1}}^{p_{2}} q_{n}\right|_{n=n_{1}} \mathrm{~d} p & =-\int_{p_{1}}^{p_{2}} R \cos (\alpha) \mathrm{d} p \\
& =-R \cos (\alpha)\left(p_{2}-p_{1}\right) \\
\left.\int_{p_{1}}^{p_{2}} q_{n}\right|_{n=n_{2}} \mathrm{~d} p & =\int_{p_{1}}^{p_{2}} R_{\mathrm{i}} \cos (\alpha) \mathrm{d} p \\
& =R_{\mathrm{i}} \cos (\alpha)\left(p_{2}-p_{1}\right)
\end{aligned}
$$

Using eqns (A6), (A7), and (A8) in eqn (A3) we obtain the rate of movement of the wetting front,

$$
\frac{\mathrm{d} N_{\mathrm{f}}}{\mathrm{d} t}=\frac{\left(R-R_{\mathrm{i}}\right) \cos \alpha}{\theta\left(R, N_{\mathrm{f}}\right)-\theta\left(R_{\mathrm{i}}, N_{\mathrm{f}}\right)}
$$

The rate of advance of the wetting front depends on the difference between the rainfall rate and the initial recharge $\left(R-R_{\mathrm{i}}\right)$ and the difference between the moisture distributions corresponding to $R$ and $R_{\mathrm{i}}$ at the depth of the wetting front. 